\title{
Low Prevalence of Thrombosis Prophylaxis Dose Adjustments Highlights Implications for Patient Safety
}

\author{
W. Anthony Hawkins, PharmD, BCCCP'; Susan E. Smith, PharmD, BCPS, BCCCP²; Tia M. Stitt, PharmD²; \\ Aliya Abdulla, PharmD candidate ${ }^{2}$; Trisha N. Branan, PharmD, BCCCP²; Ronald G. Hall 2nd, PharmD, MSCS ${ }^{3}$ \\ ${ }^{1}$ Department of Clinical and Administrative Pharmacy, University of Georgia College of Pharmacy and Department of Pharmacology; \\ Toxicology, Medical College of Georgia at Augusta University \\ ${ }^{2}$ Department of Clinical and Administrative Pharmacy, University of Georgia College of Pharmacy \\ ${ }^{3}$ Department of Pharmacy Practice, Texas Tech University Health Sciences Center
}

\begin{abstract}
Background: Pharmacologic thromboprophylaxis (PTP) is the mainstay prevention strategy for venous thromboembolism (VTE). PTP agents traditionally dosed, like unfractionated heparin (UFH) and enoxaparin (ENOX), are associated with failure and bleeding in obese and underweight patients, respectively.

Objectives: This study aimed to describe the prevalence of unadjusted ENOX and UFH dosing for PTP based on anthropometric measures.

Patients/Methods: This was a post-hoc, multicenter, cross-sectional analysis of critically ill adults receiving PTP with ENOX or UFH. The primary outcome was the prevalence of unadjusted PTP based on body mass index (BMI) and total body weight (TBW). Definitions for dose adjustments were developed based on existing literature. A secondary outcome was to identify factors associated with unadjusted dosing per BMI and TBW using multivariable generalized linear mixed-effect models.

Results: The nested cohort included 172 patients (ENOX=46, UFH=126). Unadjusted PTP was observed in 118 patients (68.6\%) based on BMI and 74 (43\%) per TBW. When comparing UFH to ENOX, more patients who received UFH had doses unadjusted by BMI (78.6\% vs. $41.3 \%, p<0.05)$ but not TBW (43.7\% vs. 41.3\%). Factors independently associated with unadjusted PTP per BMI were receipt of UFH (OR 6.93, 95\% Cl 1.06-8.77) or a BMI underweight or overweight/obese (OR 10.45, 95\% Cl 4.38-24.92). Having a TBW <50kg or >100kg (OR 4.85, 95\% Cl 2.15-10.96) were independently associated with unadjusted PTP based on TBW.

Conclusions: Unadjusted dosing of PTP occurs frequently in critically ill adults receiving ENOX or UFH. This was seen in body size extremes by both BMI and TBW.
\end{abstract}

Key Words: anthropometry, anticoagulants, primary prevention, obesity, venous thromboembolism

\section{Introduction}

Venous thromboembolism (VTE) incidence is higher among patients in the intensive care unit (ICU) due to high severity of illness, underlying comorbidities, immobilization, and need for mechanical ventilation.[1] VTE leads to prolonged stay, higher cost, and increased morbidity, and mortality.[2] The use of pharmacologic thromboprophylaxis (PTP) is the mainstay prevention strategy to be used alone or in combination with mechanical prophylaxis.[3] Without robust trials to stratify risks for bleeding or thrombosis in the critically ill population, multiple VTE prophylaxis guidelines make low grade recommendations that include subjective assessments, such as 'patients with a high bleed risk' or 'patients at risk for thrombosis.' $[4,5]$

\section{Corresponding author:}

W. Anthony Hawkins, PharmD, BCCCP

University of Georgia College of Pharmacy

1000 Jefferson Street, Albany, GA 31701

Email: hawkins@uga.edu

Phone: 229-312-2158; Fax: 229-312-2155
Commonly used PTP agents, such as unfractionated heparin (UFH) and enoxaparin (ENOX), have been associated with failure and bleeding in obese and underweight patients, respectively, when traditional dosing schemes are used.[6] While traditional dosing is not well defined and concerns of safety and efficacy are well documented, dosing adjustments are not commonplace. This study aimed to characterize current practice related to dosing of ENOX and UFH for PTP in ICU patients and examine the rate of unadjusted dosing of PTP based on different anthropometric criteria, including total body weight (TBW) and body mass index (BMI).

\section{Materials and Methods}

This was a post-hoc analysis of a previously published multicenter, cross-sectional, point-prevalence study that aimed to describe the withholding of PTP in the form of ENOX or UFH in ICU patients across nine institutions in the state of Georgia. The original study included all ICU patients, whereby all data was collected on a single day in March 2014, and patients that were lacking pharmacologic prophylaxis were analyzed.[7] The primary endpoint was the prevalence of unadjusted PTP based on BMI and TBW. Table 2 defines adjusted PTP dosing for UFH and ENOX based on BMI and TBW. These definitions were derived from the summation of literature regarding VTE prophylaxis in critically ill.[8-10] Secondary endpoints included 
adjustment of dose based on anthropometric stratification by TBW and BMI and identification of risk factors for unadjusted dosing. The continuous data was determined to fit a nonparametric distribution and was evaluated using Wilcoxon Rank-Sum. For all analyses, $\mathrm{p}<0.05$ was considered significant. All analyses were performed using STATA 15.

\section{Results and Discussion}

Of the 364 patients in the original study, 172 received PTP with the agents of interest and were included in this analysis. 126 patients $(73 \%)$ received UFH and 46 patients $(27 \%)$ received ENOX. The median age was higher in patients receiving UFH (64 vs. 52 years, $p=0.004$ ). Patients receiving UFH were of similar body habitus to patients in the ENOX group based on median BMI ( 27 vs. $28 \mathrm{~kg} / \mathrm{m}^{2}$ ) or median weight (77 vs. $82 \mathrm{~kg}$ ). Patients in both groups were mostly bedridden in both UFH and ENOX groups (52 vs 70\%), and of the patients receiving UFH, 61 patients (48\%) presented with renal injury versus 9 patients (20\%) of those receiving ENOX. The majority of patients were seen in an academic medical center for both UFH and ENOX groups (87 vs $91 \%$ ). A complete list of baseline characteristics are outlined in Table 1.

Currently, available literature regarding the adjustment of VTE prophylaxis do not provide clear guidance on best practices. Guidelines include limited and vague suggestions for dosing such as utilizing UFH twice or three times daily.[4,5] Recent literature suggests that underweight and overweight patients are at risk for prophylaxis failure and are increasingly at risk to bleed and clot, respectively.[8] Data for patient harm is crucial to augment therapy. Based on this information, classifications for drug dosing in this study were developed accordingly. Unadjusted PTP dosing was seen in 118 patients (69\%) based on BMI and in 74 (43\%) when using TBW. More patients who received UFH were unadjusted by $\mathrm{BMI}$ when compared to those who received ENOX ( $79 \%$ vs $41 \%, \mathrm{p}<0.05)$. The frequency of dosing regimens is described in Table 2.

Multivariable generalized linear mixed-effect models designed to identify factors independently associated with unadjusted dosing are in Table 3. A weight $<50 \mathrm{~kg}$ or $>100 \mathrm{~kg}$ (OR 4.85, 95\% $\mathrm{Cl}$ 2.15-10.96) and trauma (OR 6.03, 95\% Cl 1.28-28.44) were independently associated with unadjusted dosing per TBW. When stratified by BMI, underweight or overweight BMI (OR $10.45,95 \% \mathrm{Cl} 4.38-24.92$ ) and use of UFH (OR 6.93, 95\% Cl 1.068.77) were independently associated with unadjusted dosing. Hemoglobin greater than $9 \mathrm{~g} / \mathrm{dL}$, recent surgery, and trauma may influence the risk-to-benefit assessment for developing a bleed or thrombosis. On univariate analysis by TBW and BMI, neither an INR above 1.5 nor a platelet count less than $100 \mathrm{x}$ $10^{9} / \mathrm{L}$ statistically contributed to unadjusted dosing. While the INR and platelet count could have impacted the initial decision to prescribe VTE prophylaxis, that patient group has been previously described in the initial study.[7]
This study highlighted that a myriad of PTP dosing regimens for UFH and ENOX are used and lack uniformity. The variety of anthropometric stratification used in the literature contributes to lack of guidance for dosing in under- and overweight patients. Additionally, both small and large body sizes, defined by BMI or TBW, were independently associated with unadjusted dosing. This is the first study, to our knowledge, to evaluate how effectively these dosing strategies are translated to ICU practice.

Elucidating the optimal regimen for PTP in critically ill patients is challenging for many reasons, including an array of definitions in the literature and infrequent safety and efficacy outcomes. There is a growing body of evidence that suggests traditional dosing of PTP may not be optimal in ICU patients across all body habitus subtypes. The correlations between BMI and the incidence of VTE and bleeding highlight the need for individualized dosing recommendations in high-risk patient populations, including critically ill, underweight, and obese.[1] Our study was based in hospitals across Georgia and may not reflect practice in other geographic regions. Because the initial study was focused on the prescription of PTP, factors that could contribute to bleeding risk and impact dosing may not have been captured. Therapeutic drug monitoring of ENOX was not examined in this study, making assessment of dosing strategy difficult.

\section{Conclusion}

Unadjusted PTP dosing in critically ill adults is prevalent, regardless of which anthropometric measure is used and it has the potential to negatively impact patient outcomes. Given the frequency that PTP is prescribed in the ICU, standardized anthropometric stratifications to guide PTP dosing are necessary.

Ethics approval and consent to participate: waived Consent for publication: N/A Availability of data and materials: The datasets used and/or analyzed during the current study are available from the corresponding author of the initial manuscript from which this research was derived.

Funding: No funding was received for the development or production of this work.

Authors' contributions: WAH collected data and wrote manuscript. SES analyzed data and wrote and revised manuscript. TMS collected data and wrote manuscript. AA wrote and revised manuscript. TNB wrote and revised manuscript. RGH analyzed data and wrote manuscript. Acknowledgements: N/A Conflict of Interest Disclosure: Hawkins WA; Smith SE; Stitt TM; Abdulla A; Branan TN have no conflicts of interest to disclose.

Competing interests: $\mathrm{RGH}$ currently receives grant funding from Merck. 


\section{Abbreviations}

$\mathrm{BMI}$ - body mass index

ENOX - enoxaparin

ICU - intensive care unit

PTP - pharmacologic thromboprophylaxis

TBW - total body weight

UFH - unfractionated heparin

VTE - venous thromboembolism

\section{References}

1. Lim W, Meade M, Lauzier F, Zarychanski R, Mehta S, Lamontagne $F$, et al. Failure of anticoagulant thromboprophylaxis: risk factors in medical-surgical critically ill patients*. Crit Care Med. 2015;43(2):40110.

2. Rondina MT, Wheeler M, Rodgers GM, Draper $L$, Pendleton RC. Weight-based dosing of enoxaparin for VTE prophylaxis in morbidly obese, medically-III patients. Thrombosis research. 2010;125(3):220-3.

3. Dobesh PP, Wittkowsky AK, Stacy Z, Dager WE, Haines ST, Lopez LM, et al. Key articles and guidelines for the prevention of venous thromboembolism. Pharmacotherapy. 2009;29(4):410-58.

4. Gould MK, Garcia DA, Wren SM, Karanicolas PJ, Arcelus JI, Heit JA, et al. Prevention of VTE in nonorthopedic surgical patients: Antithrombotic Therapy and Prevention of Thrombosis, 9th ed: American College of Chest Physicians Evidence-Based Clinical Practice Guidelines. Chest. 2012;141(2 Suppl):e227S-e77S.
5. Kahn SR, Lim W, Dunn AS, Cushman M, Dentali F, AkI EA, et al. Prevention of VTE in nonsurgical patients: Antithrombotic Therapy and Prevention of Thrombosis, 9th ed: American College of Chest Physicians Evidence-Based Clinical Practice Guidelines. Chest. 2012;141(2 Suppl):e195S-e226S.

6. Sebaaly J, Covert K. Enoxaparin Dosing at Extremes of Weight: Literature Review and Dosing Recommendations. Ann Pharmacother. 2018;52(9):898-909.

7. Hawkins A, Mazzeffi M, Abraham P, Paciullo C. Prevalence and factors associated with the absence of pharmacologic venous thromboembolism prophylaxis: A cross-sectional study of Georgia intensive care units. Journal of critical care. 2016;36:49-53.

8. Vandiver JW, Ritz LI, Lalama JT. Chemical prophylaxis to prevent venous thromboembolism in morbid obesity: literature review and dosing recommendations. Journal of thrombosis and thrombolysis. 2016;41(3):475-81.

9. Lee YR, Blanco DD. Efficacy of standard dose unfractionated heparin for venous thromboembolism prophylaxis in morbidly obese and non-morbidly obese critically III patients. J Thromb Thrombolysis. 2017;44(3):386-91.

10. Patanwala AE, Seaman SM, Kopp BJ, Erstad BL. Heparin dosing for venous thromboembolism prophylaxis in obese hospitalized patients: An observational study. Thromb Res. 2018;169:152-6. 
Table 1. Baseline Characteristics

\begin{tabular}{|c|c|c|c|c|}
\hline Patient Characteristics & $\begin{array}{l}\text { Entire cohort } \\
\qquad N=172\end{array}$ & $\begin{array}{c}\text { UFH } \\
\mathrm{N}=126\end{array}$ & $\begin{array}{l}\text { ENOX } \\
\mathrm{N}=46\end{array}$ & $\begin{array}{c}\text { p-value } \\
\text { UFH vs ENOX }\end{array}$ \\
\hline Age in years, median (IQR) & $61(48,70)$ & $63.5(52,71)$ & $52(35,68)$ & 0.004 \\
\hline Male $(n, \%)$ & $91(52.9)$ & $63(50.0)$ & $28(60.9)$ & 0.21 \\
\hline Weight in kg, median (IQR) & $80(64,96.3)$ & $77.1(59.6,95.4)$ & $81.5(67.9,98)$ & 0.21 \\
\hline BMI in $\mathrm{kg} / \mathrm{m}^{2}$, median (IQR) & $27.4(22.5,31.8)$ & $27.4(22.4,31.8)$ & $27.8(23.3,31.8)$ & 0.48 \\
\hline SOFA score, median (IQR) & $5(3,7)$ & $5(3,7)$ & $4(3,6)$ & 0.14 \\
\hline ICU day, median (IQR) & $5(3,12)$ & $5(2,10)$ & $8(4,15)$ & 0.02 \\
\hline Hospital day, median (IQR) & $7(3,14)$ & $7(3,12)$ & $8(4,19)$ & 0.07 \\
\hline $\begin{array}{l}\text { Reason for ICU admission, } \mathrm{n}(\%) \\
\text { Central nervous system } \\
\text { Respiratory } \\
\text { Cardiovascular } \\
\text { Postoperative care } \\
\text { Infection/sepsis } \\
\text { Bleeding } \\
\text { Other }\end{array}$ & $\begin{array}{c}21(12.2) \\
50(29.1) \\
22(12.8) \\
27(15.7) \\
21(12.2) \\
8(4.7) \\
23(13.4)\end{array}$ & $\begin{array}{c}11(8.7) \\
36(28.6) \\
19(15.1) \\
23(18.3) \\
19(15.1) \\
6(4.8) \\
12(9.5)\end{array}$ & $\begin{array}{c}10(21.7) \\
14(30.4) \\
3(6.5) \\
4(8.7) \\
2(4.4) \\
2(4.4) \\
11(23.9)\end{array}$ & 0.007 \\
\hline Less than 48 hrs post op, $\mathrm{n}(\%)$ & $30(17.4)$ & $21(16.7)$ & $9(19.6)$ & 0.66 \\
\hline $\begin{array}{l}\text { Physical activity, } \mathrm{n}(\%) \\
\text { Mobile } \\
\text { Restricted } \\
\text { Bedridden } \\
\end{array}$ & $\begin{array}{l}20(11.6) \\
54(31.4) \\
98(57.0)\end{array}$ & $\begin{array}{l}17(13.5) \\
43(34.1) \\
66(52.4)\end{array}$ & $\begin{array}{c}3(6.5) \\
11(23.9) \\
32(69.6) \\
\end{array}$ & 0.12 \\
\hline Hemoglobin </=9g/dL, n (\%) & $80(46.5)$ & $59(46.8)$ & $21(45.7)$ & 0.89 \\
\hline INR $>1.5, \mathrm{n}(\%)$ & $80(46.5)$ & $55(43.7)$ & $25(54.4)$ & 0.21 \\
\hline Platelets $</=100 \times 10^{\wedge} 3, \mathrm{n}(\%)$ & $15(8.7)$ & $13(10.3)$ & $2(4.4)$ & 0.22 \\
\hline Renal injury, $\mathrm{n}(\%)$ & $70(40.7)$ & $61(48.4)$ & $9(19.6)$ & 0.001 \\
\hline Hospital Characteristics & $\begin{array}{l}\text { Entire cohort } \\
\qquad \mathrm{N}=172\end{array}$ & $\begin{array}{c}\text { UFH } \\
\mathrm{N}=126\end{array}$ & $\begin{array}{l}\text { ENOX } \\
N=46\end{array}$ & p-value UFH vs ENOX \\
\hline Academic, n (\%) & $152(88.4)$ & $110(87.3)$ & $42(91.3)$ & 0.47 \\
\hline Community, $\mathrm{n}(\%)$ & $20(11.6)$ & $16(12.7)$ & $4(8.7)$ & \\
\hline Pharmacist participation in daily rounds, $\mathrm{n}(\%)$ & $160(93.0)$ & $121(96.0)$ & $39(84.8)$ & 0.10 \\
\hline $\begin{array}{l}\text { ICU type, } \mathrm{n}(\%) \\
\text { Medical } \\
\text { Surgical } \\
\text { Cardiac surgery } \\
\text { Cardiac care unit } \\
\text { Trauma surgery } \\
\text { Neuroscience } \\
\text { Mixed }\end{array}$ & $\begin{array}{c}61(35.5) \\
39(22.7) \\
20(11.6) \\
12(7.0) \\
9(5.2) \\
22(12.8) \\
9(5.2)\end{array}$ & $\begin{array}{c}56(44.4) \\
24(19.1) \\
15(11.9) \\
8(6.4) \\
3(2.4) \\
13(10.3) \\
7(5.6)\end{array}$ & $\begin{array}{c}5(10.9) \\
15(32.6) \\
5(10.9) \\
4(8.7) \\
6(13.0) \\
9(19.6) \\
2(4.4)\end{array}$ & 0.001 \\
\hline
\end{tabular}

ENOX-enoxaparin; UFH-unfractionated heparin; BMI-body mass index; SOFA-sequential organ failure assessment; ICU-intensive care unit 
Table 2. Definitions and frequency of dosing by agent and anthropometric stratification

\begin{tabular}{|c|c|c|c|c|c|c|c|}
\hline \multicolumn{8}{|c|}{ UFH } \\
\hline Dose & $\begin{array}{c}\text { BMI <18 } \\
(n=11)\end{array}$ & $\begin{array}{c}\text { BMI 18-24.9 } \\
(n=39)\end{array}$ & $\begin{array}{c}\text { BMI 25-30 } \\
(n=34)\end{array}$ & $\begin{array}{l}\text { BMI >30 } \\
(n=23)\end{array}$ & $\begin{array}{c}\text { TBW } \\
<50 \mathrm{~kg} \\
(n=11)\end{array}$ & $\begin{array}{c}\text { TBW 50- } \\
100 \mathrm{~kg} \\
(\mathrm{n}=93)\end{array}$ & $\begin{array}{c}\text { TBW }>100 \\
\text { kg } \\
(n=22)\end{array}$ \\
\hline $\begin{array}{c}\text { Adjusted dose } \\
\text { (units) }\end{array}$ & $5000 \mathrm{Q} 12 \mathrm{H}$ & $5000 \mathrm{Q} 8 \mathrm{H}$ & $\geq 7500 \mathrm{Q} 8 \mathrm{H}$ & $\geq 7500 \mathrm{Q} 8 \mathrm{H}$ & $\begin{array}{l}5000 \\
\mathrm{Q} 12 \mathrm{H}\end{array}$ & $5000 \mathrm{Q} 8 \mathrm{H}$ & $\geq 7500 \mathrm{Q} 8 \mathrm{H}$ \\
\hline $\begin{array}{c}5000 \text { units } \\
\mathrm{Q} 12 \mathrm{H}\end{array}$ & 3 & 19 & 12 & 4 & 7 & 31 & 5 \\
\hline 5000 units Q8H & 8 & 20 & 21 & 17 & 4 & 61 & 14 \\
\hline 7500 units $\mathrm{Q} 8 \mathrm{H}$ & 0 & 0 & 0 & 2 & 0 & 0 & 3 \\
\hline $\begin{array}{c}10,000 \text { units } \\
\mathrm{Q} 8 \mathrm{H}\end{array}$ & 0 & 0 & 1 & 0 & 0 & 1 & 0 \\
\hline Overdose (\%) & 73 & 0 & 0 & 0 & 36 & 1 & 0 \\
\hline Underdose (\%) & 0 & 51 & 97 & 91 & 0 & 33 & 86 \\
\hline \multicolumn{8}{|c|}{ ENOX } \\
\hline Dose & $\begin{array}{c}\text { BMI <18 } \\
(n=1)\end{array}$ & $\begin{array}{c}\text { BMI 18-24.9 } \\
(n=14)\end{array}$ & $\begin{array}{c}\text { BMI 25-30 } \\
(n=14)\end{array}$ & $\begin{array}{c}\text { BMI >30 } \\
(n=7)\end{array}$ & $\begin{array}{c}\text { TBW } \\
<50 \mathrm{~kg} \\
(n=2)\end{array}$ & $\begin{array}{c}\text { TBW } \\
50-100 \mathrm{~kg} \\
(\mathrm{n}=36)\end{array}$ & $\begin{array}{l}\text { TBW > } \\
100 \mathrm{~kg} \\
(\mathrm{n}=8)\end{array}$ \\
\hline $\begin{array}{c}\text { Adjusted dose } \\
\text { (mg)/day }\end{array}$ & 30 & 40 & $\geq 60$ & $\begin{array}{c}\text { BMI 30-35: } \\
\geq 60 \\
\text { BMI >35: } \\
\geq 80\end{array}$ & 30 & 40 & $\begin{array}{c}\text { TBW } 100- \\
150: \geq 60 \\
\text { TBW >150: } \\
\geq 80\end{array}$ \\
\hline $30 \mathrm{mg} \mathrm{Q24H}$ & 0 & 0 & 2 & 0 & 0 & 3 & 1 \\
\hline $40 \mathrm{mg} \mathrm{Q24H}$ & 1 & 12 & 3 & 5 & 1 & 21 & 4 \\
\hline $30 \mathrm{mg} \mathrm{Q12H}$ & 0 & 2 & 9 & 1 & 1 & 12 & 2 \\
\hline $40 \mathrm{mg} \mathrm{Q12H}$ & 0 & 0 & 0 & 0 & 0 & 0 & 0 \\
\hline $120 \mathrm{mg} \mathrm{Q12H}$ & 0 & 0 & 0 & 1 & 0 & 0 & 1 \\
\hline Overdose (\%) & 100 & 14 & 0 & 0 & 100 & 33 & 0 \\
\hline Underdose (\%) & 0 & 0 & 36 & 86 & 0 & 8 & 63 \\
\hline
\end{tabular}

UFH-unfractionated heparin; BMI-body mass index; ENOX-enoxaparin; TBW-total body weight BMI expressed as $\mathrm{kg} / \mathrm{m}^{2}$; TBW expressed as $\mathrm{kg}$ 
Table 3: Multivariable analyses of factors associated with unadjusted PTP by TBW and BMI

\begin{tabular}{|c|c|c|}
\hline Characteristic & Odds Ratio & $95 \% \mathrm{Cl}$ \\
\hline \multicolumn{3}{|c|}{ Independent Factors based on Total Body Weight } \\
\hline TBW $<50$ or $>100$ kilograms & 4.85 & 2.15-10.96 \\
\hline Unfractionated heparin & 1.89 & $0.74-4.88$ \\
\hline Trauma & 6.03 & $1.28-28.44$ \\
\hline Hemoglobin $>9 \mathrm{~g} / \mathrm{dL}$ & 1.66 & $0.83-3.34$ \\
\hline Surgery within 48 hours & 2.20 & $0.88-5.50$ \\
\hline \multicolumn{3}{|c|}{ Independent Factors based on Body Mass Index } \\
\hline $\mathrm{BMI}<18$ or $>25 \mathrm{~kg} / \mathrm{m}^{2}$ & 10.45 & 4.38-24.92 \\
\hline Unfractionated heparin & 6.93 & $1.06-8.77$ \\
\hline Trauma & 0.46 & $0.12-1.82$ \\
\hline Hemoglobin $>9 \mathrm{~g} / \mathrm{dL}$ & 0.94 & $0.42-2.08$ \\
\hline Surgery within 48 hours & 0.77 & $0.29-2.08$ \\
\hline
\end{tabular}

TBW-total body weight; BMI-body mass index 